\title{
Editorial
}

\section{Todo reconocimiento es un reto}

$E$

l reciente éxito de nuestra Universidad en el proceso de Licenciamiento debe servirnos para reflexionar sobre varios aspectos que se entremezclan y, por ello, podrían perderse de vista si no se depuran a tiempo. En primer lugar, nos regocija compartir este reconocimiento con el alumnado, los docentes e investigadores y, también, con el personal que administra el quehacer de nuestra comunidad universitaria. No obstante, es imprescindible poner en contexto estas palabras optimistas para explicar cómo se inició este proceso, además de resaltar la mirada crítica con la cual debemos seguir forjando una visión de autonomía y excelencia, que son las principales señales que nos distinguen.

Hacia noviembre del 2015 la Sunedu inició el control de calidad que obliga el cumplimiento de estándares en infraestructura, equipamiento, personal docente, acceso a las tecnologías de la información y comunicación, laboratorios, bibliotecas, auditorios etc., como requisito para autorizar a una institución de Educación Superior el otorgamiento de grados y títulos para el servicio profesional.

La Universidad Ricardo Palma inició este proceso con la entrega de la documentación requerida, de acuerdo a los formatos establecidos por la Sunedu, la cual asignó un número de expediente a la información que le hicimos llegar con el fin de realizar el seguimiento. Posteriormente, una comisión especial elaboró un informe tras verificar de manera presencial que los documentos enviados reflejaban la realidad de nuestra institución. Tras revisarse el informe se procedió a emitir la resolución que reconocía nuestro Licenciamiento.

Resultó abrumadora la cantidad de documentos generados como fuentes de verificación para cumplir con los estándares. La ley indicaba que asi lo hiciéramos $y$, aunque mantenemos una cierta distancia sobre el estado actual de algunos asuntos referidos a las acreditaciones, somos respetuosos del Estado de derecho. Por ello, consideramos positivo participar en un proceso de mejoras educativas, sin dejar de mencionar los peligros inherentes del sistema elegido para ese fin. Anhelamos que se pueda corregir a tiempo todo aquello que desmerece el nuevo enfoque de la Educación Superior en nuestro pais. 
Los procesos compulsivos de acreditación no necesariamente logran los resultados esperados. Pueden exaltar, sin proponérselo, la práctica de lo que se ha dado en llamar el "resultadismo". Es posible que una institución universitaria fundamentada en un modelo de negocio, que relega a un segundo plano -o a ninguno- la construcción sólida de su visión curricular, pueda acumular la batahola de documentos exigidos por ley y realizar mejoras de último minuto, es decir, maquillarse lo mejor posiblepara encajar en el molde que demanda la política de turno. Pero ninguna sociedad cambia por decreto; por eso, desde esta tribuna hemos defendido firmemente la libertad frente al autocontrol, ideal este que adquiere su mayor expresión en la autonomía universitaria.

Un servicio educativo universitario de calidad, que ofrezca una formación multidisciplinaria y de perfeccionamiento continuo, debe arraigarse en la incorporación de valores ciudadanos y en la difusión de una cultura de paz que nazca y se dirija siempre hacia un horizonte humanista. Solo asi se podrá garantizar la reflexión académica que nuestro país necesita.

La sociedad nos ha dado su aval. Nuestra labor se ha distinguido por décadas y ese voto de confianza ha sido renovado con el Licenciamiento. Ello no nos hace olvidar los retos propios, asi como las mejoras continuas que, previamente, habiamos programado como institución. Sin envanecernos o sin perder el rumbo independiente, aceptamos todo reconocimiento como el desafio que representa. En primer lugar, por las altas expectativas que la comunidad pone en nuestro desempeño y, finalmente, porque no olvidamos el compromiso exigente que nos hemos trazado en nuestra propia casa de estudios.

\section{Dr. Iván Rodríguez Chávez}

Rector 